\title{
A clinical appraisal of different Z-score equations for aortic root assessment in the diagnostic evaluation of Marfan syndrome
}

\author{
Roland R.J. van Kimmenade, MD, PhD ${ }^{1,2}$, Marlies Kempers, MD, PhD³, Menko-Jan de Boer, MD, PhD², \\ Bart L. Loeys, MD, $\mathrm{PhD}^{3,4}$ and Janneke Timmermans, MD ${ }^{2}$
}

Purpose: Aortic sinus diameter dilatation expressed as a $Z$-score $>2.0$ is diagnostic in Marfan syndrome. In addition to the classic equation ( $Z 1)$ for calculating $Z$-scores, two new equations were recently introduced $(\mathrm{Z} 2$ and $\mathrm{Z3})$.

Methods: We studied the effects of obesity, age, and the absolute cut point of $40 \mathrm{~mm}$ on these three equations in 2,674 echocardiographic measurements of 260 patients with Marfan syndrome.

Results: Diameters $\geq 40 \mathrm{~mm}$ were associated with $\mathrm{Z} 1$ scores $<2.0$ in 109 measurements (11.0\%; 35 patients), Z2 scores $<2.0$ in 37 measurements $(3.8 \% ; 13$ patients), and Z3 scores $<2.0$ in 24 measurements $(2.4 \% ; 11$ patients). Mean diameters increased after the 40 th birthday: 42.0 (37.3-44.8 $\mathrm{mm}$ interquartile range) to 42.5 (39.0$45.0 \mathrm{~mm}$ interquartile range; $P=$ not significant) and mean $\mathrm{Z} 1$ scores

\section{INTRODUCTION}

The clinical outcome in subjects with Marfan syndrome (MFS) is largely determined by the prevalence or prevention of type A ascending aorta dissection. Since the introduction of the Bentall procedure in 1968, the prognosis in patients suffering from MFS has improved significantly. ${ }^{1,2}$ The incidence of type A dissection is mainly related to the diameter of the aortic root, and the widest aortic diameters are associated with the highest risk for type A dissection. ${ }^{3,4}$

Of note, to diagnose aortic root dilatation, it is essential to have clearly defined normal values of aortic diameters. These normal values were first established by Roman and colleagues in 1989 and were based on data derived from 135 adult subjects. The proposed equation for adults relates to body surface area (BSA) and consists of two formulas for calculating normal aortic sinus diameters, respectively, in subjects between 20 and 40 years, and in those older than 40 years, whereas it suggests a linear correlation between the aortic diameter and BSA. ${ }^{5}$ A dilated aortic root is defined as a $Z$-score $\geq 2.0$, which corresponds with a diameter $\geq 2.0 \mathrm{SD}$ above normal (also see Methods section). More recently, however, Devereux et al. ${ }^{6}$ proposed two new equations (one corrects for BSA, the other corrects for body height) for the calculation of the normal values decreased from 3.60 to $2.17(P<0.01)$, whereas $\mathrm{Z} 2$ and $\mathrm{Z} 3$ scores tended to increase (Z2: 3.04-3.27; Z3: 3.39-3.55; $P=$ not significant for both). Comparing $Z$-scores between patients with body mass index $<25 \mathrm{~kg} / \mathrm{m}^{2}$ (group A) and those with body mass index $\geq 25 \mathrm{~kg}$ / $\mathrm{m}^{2}$ (group $\mathrm{B}$ ), median $\mathrm{Z} 1$ scores differed between groups $(\mathrm{Z} 1=3.00$ in group $\mathrm{A}, \mathrm{Z1}=1.78$ in group $\mathrm{B} ; P=0.012)$, whereas $\mathrm{Z} 2(\mathrm{Z} 2=2.82$ in group $A, Z 2=2.47$ in group $B ; P=0.52)$ and $Z 3$ scores $(Z 3=2.72$ in group $\mathrm{A}, \mathrm{Z2}=3.12$ in group $\mathrm{B} ; P=0.32$ ) did not.

Conclusion: $\mathrm{Z} 1$ scores are inferior to $\mathrm{Z} 2$ and $\mathrm{Z} 3$ scores in Marfan syndrome. In particular, the Z3 score, correcting aortic sinus diameter for body height, seems excellent.

Genet Med 2013:15(7):528-532

Key Words: aorta; diagnosis; echocardiography; Marfan syndrome

of aortic root diameters. ${ }^{7}$ These equations are derived from a much larger population consisting of more than 1,200 subjects, and in addition to BSA or height, they also take into account age and gender.

Of note, the recently revised criteria for the diagnosis of MFS have given more weight to aortic root dilation, considering a dilated aortic root defined as an aortic sinus diameter with a $Z$-score $\geq 2.0$ as one of the most important characteristics for making the diagnosis of MFS. ${ }^{8}$ The decision to include the $Z$-score in the diagnostic criteria for MFS not only gives more weight to aortic root dilation but also to the calculation of the Z-score itself.

Yet there is debate about whether normal values of the aortic root can be extrapolated linearly (as in the classic $Z$ score formulas from Roman et al..$^{5}$ ) or whether any aortic sinus diameter $\geq 40 \mathrm{~mm}$ should be considered dilated. ${ }^{9}$ Furthermore, due to the substantial increase in prevalence of obesity in our modern society, the effect of weight gain on $Z$-scores should be evaluated, because body weight (via BSA) is an important parameter in the calculation of normal values in the classic equation. Finally, the equation by Roman et al. ${ }^{5}$ discriminates between subjects younger than 40 years and those older than 40 years, which may have important consequences when evaluating aortic root

\footnotetext{
${ }^{1}$ Department of Cardiology, University Medical Centre Utrecht, Utrecht, The Netherlands; ${ }^{2}$ Department of Cardiology, St. Radboud University Medical Centre, Nijmegen, The Netherlands; ${ }^{3}$ Department of Clinical Genetics, St. Radboud University Medical Centre, Nijmegen, The Netherlands; ${ }^{4}$ Center for Medical Genetics, Antwerp University Hospital \& University of Antwerp, Antwerp, Belgium. Correspondence: Janneke Timmermans (J.Timmermans@cardio.umcn.nl) 
diameters in subjects around their 40th birthday. Therefore, we analyzed the $Z$-scores based on the different equations in our Marfan patients' registry and compared the impact of obesity, age, and absolute diameter on the different $Z$-scores.

\section{MATERIALS AND METHODS}

\section{Patients}

All studied patients were included between January 1987 and April 2011 in our ongoing registry and were referred by general practitioners and/or cardiologists to our university hospital and seen by our specialized Marfan outpatient clinic team. This team consists of cardiologists, clinical geneticists, and ophthalmologists and adheres to standard follow-up protocols including an annual echocardiogram. For analyses, we used all visits, first as well as follow-up visits, of these patients between January 1987 and April 2011.

\section{Echocardiography}

In addition to standard images, echocardiographic evaluation included measurements of the diameters at the levels of

Table 1 Baseline characteristics on first presentation at the outpatient clinic

\begin{tabular}{lc} 
Characteristic & $\mathbf{N}=\mathbf{2 6 0}$ \\
\hline Demographic characteristic & $122(47 \%)$ \\
\hline Female gender (\%) & $30( \pm 12)$ \\
Age (years) & $186( \pm 12)$ \\
Height (cm) & $75( \pm 16)$ \\
Weight $(\mathrm{kg})$ & $1.93( \pm 0.37)$ \\
Body surface area $\left(\mathrm{m}^{2}\right)$ & $21.6( \pm 4.3)$ \\
Body mass index $\left(\mathrm{kg} / \mathrm{m}^{2}\right)$ & $127(49 \%)$ \\
Lens luxation at first presentation $(\%)$ & $89(34 \%)$ \\
$\beta$-Blocker therapy at first presentation $(\%)$ & \\
\hline Echocardiographic characteristic & $88(34 \%)$ \\
Mitral valve prolapse $(\%)$ & $24( \pm 3.6)$ \\
Aortic annulus diameter $(\mathrm{mm})$ & $41( \pm 9.8)$ \\
Aortic sinus diameter $(\mathrm{mm})$ & $32( \pm 6.3)$ \\
Ascending aorta diameter $(\mathrm{mm})$ & $2.83(1.16-4.34)$ \\
Z1 score & $2.78(1.45-4.29)$ \\
Z2 score & $2.75(1.18-4.75)$ \\
\hline Z3 score & \\
\hline
\end{tabular}

Data are presented as mean $( \pm S D)$ or median $(I Q R)$.

$\mathrm{IQR}$, interquartile range.

Table 2 Evaluation of aortic sinus measurements $\geq 40 \mathrm{~mm}$ and their correlation with a Z-score $<2.0$ according to the three equations

\begin{tabular}{lcc} 
& Measurements & $\begin{array}{c}\text { Patients } \\
\text { involved }\end{array}$ \\
\hline Total & 2,674 & 260 patients \\
Diameter $\geq 40 \mathrm{~mm}$ & $985(36.8 \%)$ & \\
Diameter $\geq 40 \mathrm{~mm}$ and Z1 score $<2.0$ & $109(11.0 \%)$ & 35 patients \\
Diameter $\geq 40 \mathrm{~mm}$ and Z2 score $<2.0$ & $37(3.8 \%)$ & 13 patients \\
Diameter $\geq 40 \mathrm{~mm}$ and Z3 score $<2.0$ & $24(2.4 \%)$ & 11 patients \\
\hline
\end{tabular}

the aortic valve annulus, the sinuses of Valsalva, the sinotubular junction, and ascending aorta from leading edge to leading edge in the parasternal long axis view. Measurements were performed end-diastolic, and the average of three measurements was used for Z-score calculation.

\section{Calculations and equations}

On the basis of sinus diameters measured as described above, different $Z$-scores were measured for comparison:

Z1 (Cornell $Z$-score by Roman et al. ${ }^{5}$ ):

In subjects aged 20-40: mean predicted aortic root diameter $(\mathrm{AR})(\mathrm{cm})$ for $\mathrm{BSA}=0.97+1.12^{*} \mathrm{BSA}$

$\mathrm{Z}=$ (measured root diameter - predicted $\mathrm{AR}) / \mathrm{SD}$ with an SD of $0.24 \mathrm{~cm}$

In subjects aged $>40$ : mean predicted AR $(\mathrm{cm})$ for BSA $=1.92+0.74 \times$ BSA

$\mathrm{Z}=$ (measured root diameter - predicted $\mathrm{AR}) / \mathrm{SD}$ with an $S D$ of $0.37 \mathrm{~cm}$

$\mathrm{Z} 2$ (new $Z$-score normalized for BSA by Devereux et al. ${ }^{6}$ ): Mean predicted AR $(\mathrm{cm})$ for $\mathrm{BSA}=2.423+($ age $\times$ $0.009)+(\mathrm{BSA} \times 0.461)-(\operatorname{sex} \times 0.267)$

$\mathrm{Z}=$ (measured diameter - predicted $\mathrm{AR}) / \mathrm{SD}$ with an $\mathrm{SD}$ of $0.261 \mathrm{~cm}$

Sex: male $=1$, female $=2$

Z3 (new $Z$-score normalized for height by Devereux et al. ${ }^{6}$ ): Mean predicted AR $(\mathrm{cm})$ for length $=1.519+($ age $\times$ $0.010)+(\mathrm{H} \times 0.10)-(\operatorname{sex} \times 0.247)$

$\mathrm{Z}=$ (measured diameter - predicted $\mathrm{AR}) / \mathrm{SD}$ with an $\mathrm{SD}$ of $0.215 \mathrm{~cm}$

Sex: male $=1$, female $=2$

BSA according to Du Bois and Du Bois ${ }^{10}$ :

BSA $\left(\mathrm{m}^{2}\right)=(0.007184 \times \mathrm{H})^{0.725} \times(\mathrm{W})^{0.425}$

$\mathrm{H}=$ height in $\mathrm{cm}, \mathrm{W}=$ weight in $\mathrm{kg}$.

\section{Statistical analyses}

Data are presented as median with intraquartile ranges for nonnormally distributed variables and means \pm SD for all other continuous variables. The Kolmogorov-Smirnov test was used to test distribution. The two-tailed independent Student's $t$-test was used for testing normally distributed parameters, and the Mann-Whitney $U$-test was applied for nonnormally distributed parameters. Statistical analyses were conducted with the use of SPSS software, version 19 (SPSS, Chicago, IL).

\section{RESULTS}

Between January 1987 and April 2011, 260 adult patients with MFS were seen at least annually by protocol in our outpatient clinic. Baseline characteristics of all patients at their first adult visit are depicted in Table 1. Mean age at first presentation was $30( \pm 12 \mathrm{SD})$ years, 122 subjects were female $(47 \%)$, and mean body mass index (BMI) at first visit was $21.6( \pm 4.3 \mathrm{SD})$ $\mathrm{kg} / \mathrm{m}^{2}$. During follow-up, 215 patients remained free of events, 33 patients underwent aortic surgery, and 12 patients died (of which 8 patients died from an identified noncardiac cause). 
After patients had undergone aortic root surgery, they were excluded from further study, which resulted in 2,674 echocardiograms of aortic root diameters free of surgery.

\section{Aorta sinus diameter $>40 \mathrm{~mm}$}

In 985 of the 2,674 measurements, an aortic sinus diameter $\geq 40 \mathrm{~mm}$ was found. According to the $\mathrm{Z1}$ equation, this was associated with a Z1 score $<2.0$ in 109 measurements, which were derived from 35 different patients, i.e., $11.0 \%$ of the diameters $\geq 40 \mathrm{~mm}$ or $13.5 \%$ of all included patients. According to the $\mathrm{Z} 2$ and $\mathrm{Z} 3$ equations, an aortic sinus diameter $\geq 40 \mathrm{~mm}$ resulted
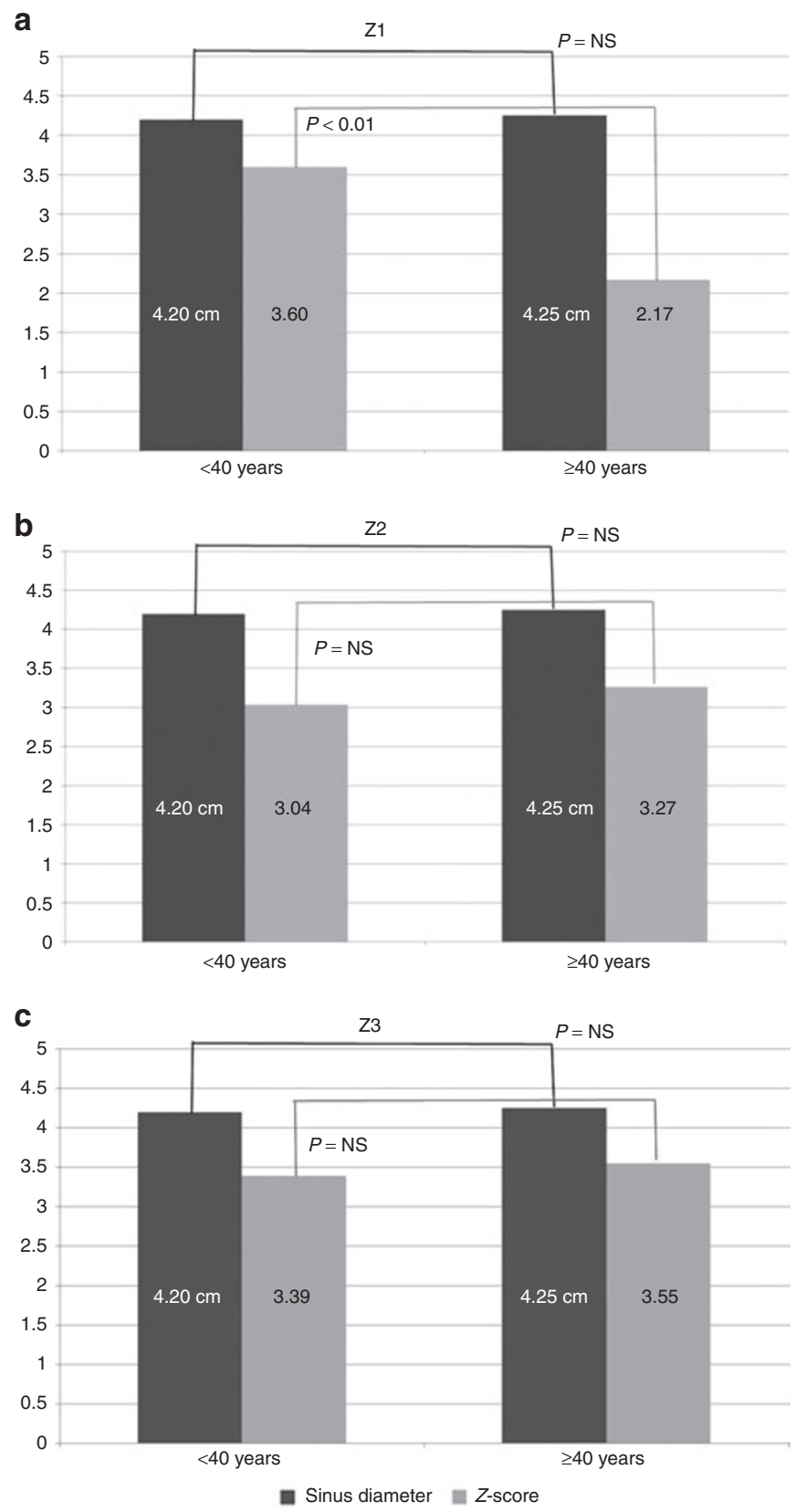

Figure 1 Trends in absolute aortic root diameters and Z-scores in subjects just before and after turning 40, using the (a) Z1, (b) Z2, or (c) Z3 equation. NS, not significant. in a $Z$-score $<2.0$ in only $37(3.8 \%)$ measurements (obtained in 13 different patients) and $24(2.4 \%)$ measurements (obtained in 11 different patients), respectively. Results are also depicted in Table 2.

\section{Age}

During follow-up, 40 patients passed the age threshold of 40 years. When comparing the aortic sinus measurements in these patients before and after turning 40 years of age, median sinus diameters increased from $42.0 \mathrm{~mm}$ (37.3-44.8 intraquartile range) to $42.5 \mathrm{~mm}$ (39.0-45.0 interquartile range), but the change was not significant. When calculating matching $Z$-scores, Z1 scores before and after turning 40 decreased significantly from $Z 1=3.60$ to $Z 1=2.17(P<0.01)$. In $16(40 \%)$ patients, this resulted in a decrease in $Z 1$ score $\geq 2.0$ to a $Z 1$ score $<2.0$. In contrast, Z2 and Z3 scores increased slightly but not significantly (Z2 from 3.04 to 3.27 and $Z 3$ from 3.39 to 3.55; $P=$ not significant for both) (Figure 1a-c).

\section{BMI and obesity}

Baseline characteristics and aortic root measurements in the cohorts leading to the establishment of the $\mathrm{Z} 1$ formulas were collected around 1988, whereas data from the Z2/Z3 cohort were collected around 2009-2010.,7 According to the data from the National Health and Nutrition Examination Survey, during the time period between the measurements of the $\mathrm{Z1}$ and Z2/Z3 cohort, the mean weight of male and female inhabitants of the United States increased from 82.3 and $69.5 \mathrm{~kg}$, respectively, to $88.3 \mathrm{~kg}(+6.0 \mathrm{~kg})$ and $74.7 \mathrm{~kg}(+5.2 \mathrm{~kg})$, whereas mean height only slightly increased from $175.4 \mathrm{~cm}$ (males) and $161.8 \mathrm{~cm}$ (females) to $176.3 \mathrm{~cm}$ (males; $+0.9 \mathrm{~cm}$ ) and $162.2 \mathrm{~cm}$ $(+0.4 \mathrm{~cm}))^{11,12}$ To study the effects of these obesity trends on aortic root evaluation, we compared the effect of the hypothetical addition of $5.0 \mathrm{~kg}$ body weight on the different $Z$-scores.

In 1,569 of the 2,674 aortic root measurements, weight and height data were both documented in the same session. In 453 (28.8\%) of these measurements, a Z1 score $<2.0$ was computed, whereas in 373 (23.7\%) measurements, a Z2 score $<2.0$ was calculated. The addition of $5.0 \mathrm{~kg}$ to the measured body weight leads to a significant increase in BSA from 2.02 to 2.07

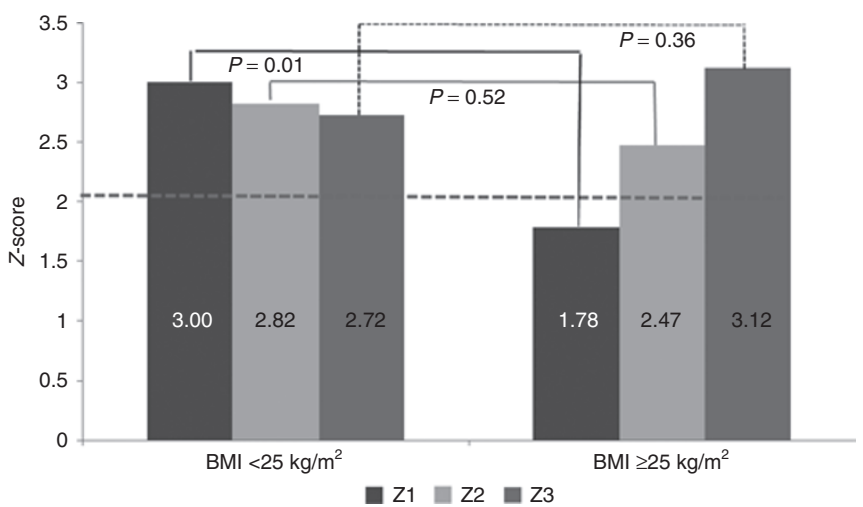

Figure 2 Differences between the three Z-scores when dividing the study population according to BMI. BMI, body mass index. 
$\mathrm{m}^{2}(P<0.01)$ paralleled by a significant decrease in median $\mathrm{Z} 1$ scores (from 2.97 to 2.72; $P<0.01$ ) and $\mathrm{Z} 2$ scores (from 3.08 to $2.97 ; P<0.01$ ). Furthermore, the number of measurements resulting in a Z1 score $<2.0$ increased by 70 measurements from $453(28.8 \%)$ to $523(33.3 \%)$ measurements and the measurements leading to a Z2 score $<2.0$ increased from 373 (23.7\%) to $420(26.8 \%)$ measurements. Of note, given that weight is not a parameter in the Z3 equation, changes in body weight will not affect the $\mathrm{Z} 3$ equation.

Second, in 218 patients, BMI data were available at the moment of their baseline echocardiogram. We divided this population into two groups: a nonobese group A with a BMI $<25 \mathrm{~kg} /$ $\mathrm{m}^{2}(n=176)$ and an obese group B with a BMI $\geq 25 \mathrm{~kg} / \mathrm{m}^{2}(n$ $=42)$ at their first visit. Of note, when we compared different $Z$-scores between these two groups, we found that the median $\mathrm{Z1}$ scores different significantly between the two groups $(\mathrm{Z1}=$ 3.00 in group $A$ and $Z 1=1.78$ in group $B ; P=0.012$ ) whereas the $\mathrm{Z} 2$ score $(\mathrm{Z} 2=2.82$ in group $\mathrm{A}, \mathrm{Z} 2=2.47$ in group $\mathrm{B} ; \mathrm{P}=$ $0.52)$ and the $Z 3$ score $(Z 3=2.72$ in group $A, Z 2=3.12$ in group B; $P=0.32)$ did not. These results are also depicted in Figure 2.

\section{DISCUSSION}

In this study, we compared and analyzed the clinical relevance of the implementation of three different $Z$-scores for the assessment of diameters of the ascending aorta in an established Marfan population. Evaluation of the performance of different $Z$-score calculation with clinically relevant parameters, such as age around 40 years, obesity, and aortic diameters $>40 \mathrm{~mm}$, suggest that in comparison with the classic Z1 score as published in 1989 by Roman and coworkers, ${ }^{5}$ the new Z2 and, in particular, the new Z3 score ${ }^{6}$ seem to better reflect clinical experiences and expectancies. This is of importance because recently the criteria for the diagnosis of MFS have been revised with a more important role for the diameter of the aortic sinus in confirming or rejecting the diagnosis in subjects suspected of having the syndrome. ${ }^{8}$

The classic Z1 score assumes and extrapolates a linear association between BSA and aortic sinus diameter. Several studies focusing on this issue performed in individuals with BSA or body height $>$ the 95th percentile question a linear relationship between aortic root diameter and BSA or body height in these larger subjects, ${ }^{13,14}$ because they found a threshold of $40 \mathrm{~mm}$ as an absolute maximum for a normal human aortic root diameter. On the basis of these data and our findings, Radonic et al. ${ }^{9}$ advocate also to consider an aortic root diameter $>40 \mathrm{~mm}$ as abnormal, even when the $Z$-score $<2.0$. Of note, we found that the $\mathrm{Z} 2$ and $\mathrm{Z} 3$ scores only computed a $Z$-score $<2.0$ in $3.8 \%$ (Z2) and $2.4 \%(\mathrm{Z} 3)$ of our aortic sinus measurements exceeding $40 \mathrm{~mm}$, whereas the $Z 1$ score still calculated a $Z$-score $<2.0$ in $11.8 \%$ of our sinus diameter measurements $>40 \mathrm{~mm}$. The implementation of the $\mathrm{Z} 2$ or $\mathrm{Z} 3$ equation might anticipate the notion that any human aortic root diameter $>40 \mathrm{~mm}$ should be considered abnormal.

Second, we studied the influence of turning 40 years of age on the three equations, because the classic Z1 score has this age as a cutoff for a switch in formulas. We demonstrated that turning 40 significantly decreased the Z1 score (and not the Z2 or Z3 score) in our patients. This analysis clearly shows that in this age group, it is important to realize that the different age-based formulas that constitute the $Z 1$ equation differ substantially and that $\mathrm{Z} 1$ scores in the age group around 40 years must be interpreted with caution. When applying the Z1 score in this age group, the whole clinical picture should be taken into account (e.g., absolute diameter, gender, body weight) in order to draw the correct conclusion rather than only interpreting the $\mathrm{Z1}$ score. In our population, the first presentation was at a mean age of 30 years $( \pm 12 S D)$; it should be noted that this is not an infrequent clinical situation.

Finally, we analyzed the effect of the progressive increase in body weight that has occurred during the decades between the establishment of the Z1 and Z2/Z3 formulas on the calculation of normal values of aortic root diameters. We found that especially the Z1 score is largely influenced by the subject's body weight, which may even result in falsely lower $Z$-scores. Of note, the Z3 score, which correlates with body height rather than BSA, is least influenced by an increase of weight or BMI. This correlates with the clinical judgment that an obese yet small individual may not have the same "normal" aortic root diameter as a slim but tall subject. Because we seem to be facing an "epidemic" of obesity, the implementation of the Z3 score may be a solution to cope with this phenomenon.

In conclusion, our data suggest that the classic $Z 1$ scores are inferior to the newer Z2 and Z3 scores in the evaluation of aortic root diameters in the diagnostic workup for MFS. In particular, the Z3 score, which corrects aortic sinus diameter for body height rather than BSA, seems an excellent tool in evaluating aortic root measurements for this purpose.

\section{ACKNOWLEDGMENTS}

B.L. is senior clinical investigator of the Fund for Scientific Research, Flanders (FWO, Belgium) and is supported in part by funding from the Fund for Scientific Research Flanders (FWO, Belgium) (G.0221.12) and the National Marfan Foundation (USA).

\section{DISCLOSURE}

The authors declare no conflict of interest.

\section{REFERENCES}

1. Groenink M, Lohuis TA, Tijssen JG, et al. Survival and complication free survival in Marfan's syndrome: implications of current guidelines. Heart 1999;82:499504.

2. Silverman DI, Burton KJ, Gray J, et al. Life expectancy in the Marfan syndrome. Am J Cardiol 1995;75:157-160.

3. Dapunt OE, Galla JD, Sadeghi AM, et al. The natural history of thoracic aortic aneurysms. J Thorac Cardiovasc Surg 1994;107:1323-32; discussion 1332

4. Elefteriades JA. Natural history of thoracic aortic aneurysms: indications for surgery, and surgical versus nonsurgical risks. Ann Thorac Surg 2002;74:S187780; discussion $\mathbf{S 1 8 9 2 .}$

5. Roman MJ, Devereux RB, Kramer-Fox R, O'Loughlin J. Two-dimensional echocardiographic aortic root dimensions in normal children and adults. Am J Cardiol 1989;64:507-512.

6. Devereux RB, de Simone G, Arnett DK, et al. Normal limits in relation to age, body size and gender of two-dimensional echocardiographic aortic root dimensions in persons $=15$ years of age. Am J Cardio/ 2012;110:1189-1194. 
7. Pyeritz RE, Loeys B. The 8th International Research Symposium on the Marfan syndrome and related conditions. Am J Med Genet A 2012;Part A 158A: $42-49$.

8. Loeys BL, Dietz HC, Braverman AC, et al. The revised Ghent nosology for the Marfan syndrome. J Med Genet 2010;47:476-485.

9. Radonic T, de Witte P, Groenink M, et al. Critical appraisal of the revised Ghent criteria for diagnosis of Marfan syndrome. Clin Genet 2011;80:346-353.

10. Du Bois D, Du Bois EF. Clinical calorimetry: Tenth paper a formula to estimate the approximate surface area if height and weight be known. Arch Intern Med 1916;17:863-871.
11. McDowell MA, Fryar CD, Ogden CL. Anthropometric reference data for children and adults: United States, 1988-1994. Vital Health Stat 11 2009:1-68.

12. $\mathrm{McD}$ owell $\mathrm{MA}$, Fryar $\mathrm{CD}$, Ogden $\mathrm{CL}$, Flegal $\mathrm{KM}$. Anthropometric reference data for children and adults: United States, 2003-2006. National Health Statistics Reports 2008;10:1-45.

13. Reed CM, Richey PA, Pulliam DA, Somes GW, Alpert BS. Aortic dimensions in tall men and women. Am J Cardio/ 1993;71:608-610.

14. Kinoshita N, Mimura J, Obayashi C, Katsukawa F, Onishi S, Yamazaki H. Aortic root dilatation among young competitive athletes: echocardiographic screening of 1929 athletes between 15 and 34 years of age. Am Heart J 2000;139:723-728. 